\title{
ethic@ \\ THE COMPLEXITY OF HEALTHCARE FRAUD - ETHICAL AND PRACTICAL CONSIDERATIONS
}

\author{
DINEKE SMIT ${ }^{1}$ \\ (Radboud University Nijmegen/Netherlands) \\ JAN DERKSEN ${ }^{2}$ \\ (Radboud University Nijmegen/Netherlands)
}

\begin{abstract}
When healthcare professionals suspect that healthcare fraud is being committed, they almost always find themselves in a new, unknown situation. They have many questions and feel unable to act adequately. With a growing attention on healthcare fraud, research was done on What is the right thing to do in case of presumed healthcare fraud and how to do this right? We started with a search of the literature on healthcare fraud, and the characteristics of a fraudster and a whistle-blower. For 'doing the right thing' we used Hannah Arendt and her distinction between labor, work and action. According to Arendt, the right thing to do is action. With action, the whistle-blower opens up space for other perspectives and discussion. For 'doing things right' we used the Cynefin Framework from Dave Snowden, which is based on complexity sciences. The decision model of the Cynefin Framework gives advice on how to respond. Still, revealing healthcare fraud and doing things right will always be a path of painful uncertainty.
\end{abstract}

Keywords: Ethics; Healthcare fraud; Whistle-blower; Complexity.

\section{Introduction}

When healthcare professionals suspect that healthcare fraud is being committed, they almost always find themselves in a new, unknown situation. They may have many questions and feel unable to act adequately. Have I properly seen and/or understood the suspected healthcare fraud? What am I supposed to do now? How do I know that I am doing the right thing for the right reasons? Can I speak about my suspicions without doing harm? Doing nothing is sometimes not an option. But what is the right thing to do and how can one act in the right way?

Our research question looks at 'doing the right thing' and 'doing things right' in the case of healthcare professionals suspecting healthcare fraud. The focus lies specifically on cases where the presumed fraudster (healthcare management, board) and the potential whistle-blower (healthcare professional) have a hierarchical relationship. For 'doing the 
right thing' we refer to Hanna Arendt and her distinction between labor, work and action. For 'doing things right' among other sources we refer to the Cynefin Framework by Dave Snowden, which is based on complexity sciences. We begin with a search of the literature on healthcare fraud, and the characteristics of a fraudster and a whistle-blower.

\section{Healthcare fraud}

The European Commission (2013) defines fraud as "a benefit of any nature by intentionally breaking a rule." The European Healthcare Fraud and Corruption Network (EHFCN) distinguishes four types of fraud (EHFCN 2016:10): first, charging for excessively expensive care; second, charging for services not provided; third, providing unnecessary services; and fourth, other forms of fraud or corruption, including charging individual payments for public services and fraudulent contracts and procurement practices. Besides fraud, a distinction can be made between in errors, abuse and corruption in healthcare. The EHFCN describes errors in healthcare as "unjustly obtaining a benefit of any nature by unintentionally breaking a rule" (EHFCN 2016:178). Abuse is described as "unjustly obtaining a benefit of any nature by knowingly stretching a rule or by taking advantage of an absence of rule" (idem). And, corruption can be defined as "illegally obtaining a benefit of any nature by abuse of power with third party involvement" (idem).

Thorton, Brinkhuis, Amrit and Aly (2015) categorized several types of fraud in healthcare, finding that improper coding, phantom bills and kickback schemes were the most frequent forms. Improper coding, or upcoding, is the most discussed and prevalent topic according to Thorton. In the case of upcoding, the healthcare provider claims more refunds than appropriate for the care provided. When phantom billing is the case, invoices are issued for care that has not been delivered. Kickback schemes are the case when, for instance, a psychiatrist fills a prescription with a specific brand of drug to benefit from a bonus from the pharmaceutical company.

Thompson (2013) draws a distinction between individual and institutional corruption. Individual corruption, Thompson explains, is the personal gain of individuals, while giving care within a healthcare facility. Institutional corruption is seen as the failure of the institution in preventing healthcare fraud. Brooks, Tunley, Button and Gee (2017) argue that while it is useful to have a clear definition of healthcare fraud to combat this kind of fraud, having a clear definition will not solve [all] problems with healthcare fraud in Europe. Every country will still be faced with different interpretations, laws and political will. 
Healthcare fraud activities may also be seriously obstructed by regulations, especially where the rules are complex and uncertain (as described in Portugal, Slovenia and the Netherlands), provide insufficient competences for supervisory bodies - especially in relation to privacy legislation (Italy, Netherlands) and finally, when these rules are subject to frequent changes, leading to a situation of uncertainty as the report on Lithuania indicates (Sauter, Mikkers, Vincke \& Boertjens 2017:17).

The definitions of healthcare fraud listed above are all more or less about breaking the rules. When a healthcare professional initially suspects that healthcare fraud is being committed, the meaning and correct interpretation of all information is not at the forefront of the professional's mind. A healthcare professional is neither an administrator nor a healthcare lawyer. Also, the distinctions between intentionally or unintentionally breaking rules and between personal benefit and institutional benefit are hard to judge up front. In addition, the rules, the policy and the law with regard to billing in the healthcare sector are often up for discussion. All of this creates a gray area filled with uncertainty. An unequivocal definition of fraud and corruption remains elusive and stays relative because our understanding of fraud and/or corruption is rooted in the social, political and cultural context (Brooks, Tunley, Button \& Gee 2017).

\section{The fraudster}

To be a fraudster in a healthcare setting, you do not need to be a healthcare professional. A fraudster can be a healthcare administrator, a manager, a director or major shareholder, and [of course] patients can also be fraudsters. In this research we focus on fraudsters who have a hierarchical relationship with the potential whistle-blower.

What do we know about fraudsters, about their motives, their characteristics? Brooks, Tunley, Button \& Gee (2017) describe what could be incentives for the fraudster. But first they note that healthcare fraud is often termed white-collar crime. In contrast to street crime, where the offender is seen as a criminal driven by 'cognitively defective constitutions', the white-collar fraudster is often seen as a respectable entrepreneur. White-collar crime often goes undetected and if detected, white-collar criminals are not always prosecuted and convicted. Cressy (1950) claims that the most likely reasons why a fraudster acts fraudulently is because they are under pressure, have the opportunity to commit fraud and can 
rationalize their acts. Brooks, Tunley, Button \& Gee (2017) state that fraudsters create a wall of justification; they diminish the impact and seriousness of their acts. According Ogunbanjo \& van Bogaert (2014), healthcare fraudsters rationalize their acts by considering healthcare fraud to be a victimless crime, that the organization is not harmed by their acts. "A rationalization is not an after-the-fact excuse that a perpetrator uses to justify his or her behaviour, but an integral part of the actor's motivation for the act" (Coleman1987: 411). Sorunke (2016) adds that the fraudster's capability to commit fraud is another key motivating factor. Sorunke explains that a person with low personal ethics does not even have to be confronted by pressure to commit fraud. Their personal ethics can be enough to make use of opportunities to commit fraud. Here the distinction between white-collar crime and street crime becomes very thin. Nevertheless, to commit fraud - a criminal act - there must be an intention to act inappropriately. Only when an act is characterized as "willful intent to deceive and profit from the deception" can it be prosecuted as fraud (Byrd, Powell \& Smith 2013). According to Ainsworth (2001), there need to be a motivated offender, a suitable (and vulnerable) victim and the absence of a capable guardian for a crime to be committed.

In summary, fraud in healthcare settings is often regarded as whitecollar crime. The fraudster is most likely under pressure to be successful, is capable of rationalizing their acts and probably has low personal ethics. However, to commit fraud in the legal sense, a willful intent to deceive and profit from the deception must be proven.

\section{The whistle-blower}

The term 'whistle-blower' can be traced back to the $19^{\text {th }}$ century (Martin n.d.). In those days it was normal for a policeman to blow a whistle when detecting a possible crime. By blowing the whistle, the police officer could warn the public and fellow officers. The story goes that the term whistle-blower was used to avoid terms with more negative connotations, such as 'snitch' and 'informer' (Nader 1972). Journalists began using the term in the 1960s. Martin defines the term as a "person who tries to raise the alarm about a problem and publicizes it inside and/or outside of his/her organization" (Martin n.d.).

Do whistle-blowers have particular identifying characteristics? Starkey (2000) finds little support for dispositional variables on whistle-blowers but did find situational variables that could predict the intention to blow the whistle. In other words, a situation can make a person a whistle-blower, not the specific characteristics of a person. This fits the idea that one is not 
a whistle-blower, but one can become a whistle-blower, for example when people in power would rather not reveal (possible) healthcare fraud. Whistle-blowers act in complex and contested circumstances (Mannion \& Davis 2015). Personal idiosyncrasies play a role, also whether or not the whistle-blower will be seen as a hero or troublemaker (idem). Even when the whistle-blower is seen as a hero, seldom do they live 'happily ever after'.

Whistle-blowers are normally subjected to hostility and retaliation in the form of intimidation, harassment, reprisal, dismissal and violence by their fellow colleagues and superiors and in the worst circumstances, even death (Sehgal 2017:267).

The forces released when whistle-blowers have no anonymity are many times greater. The bottom line is that such a person is destroyed by the people who want to keep the information under wraps, as I dare say after more than eighteen years of experience with whistleblowers (Smit 2017).

Purmina Sehgal (2017) collected the stories of well-known whistleblowers. These whistle-blowers include Daniel Ellsberg (Pentagon Papers during the Vietnam War), Stephen Bolsin (an anesthetist who disclosed the unnecessary death of children after open heart surgery), and Jeffrey Wigand (who revealed that tobacco companies were intentionally manipulating nicotine levels to addict smokers). Sharron Watkins (Enron), Coleen Rowley (FBI) and Cynthia Cooper (WorldCom) all exposed malpractices and manipulations, as did Bradley Manning and Edward Snowden (WikiLeaks). All their stories are about lawyers, financial problems, persistence, loss of friends, psycho-social problems and so on. Some whistle-blowers, like Satyendra Dubey (National Highways Authority India), Shanmughan Manjunath (adulterated fuel) and SP Manhantesh (reported irregularities in society involving officials and political figures) were even murdered. In the Netherlands there was a whistle-blower case at the Dutch Healthcare Authority (NZa). Arthur Gotlieb worked at the NZa as a policy advisor responsible for expensive medicine. He had reasons to believe that his supervisor(s) were too sensitive to lobbying by pharmaceutical companies. At first he followed the internal procedures to discuss his concerns but this only led to him being lumbered with new and especially impossible tasks at which he had to fail. This, in turn, led to an intern-supported attempt to get him fired or replaced. Although Gotlieb had documented all his concerns with evidence (e.g. e-mails and business weekend trips unreimbursed by the NZa) his employer gave him no support. Soon after he had presented 
his report to the managers, he committed suicide (Kalcheva 2015). Afterwards, the Dutch healthcare minister concluded that Gotlieb had been mistreated and that the NZa had not accepted any criticism.

In summary, although there is little support for dispositional variables on whistle-blowers, one may safely assume that a whistle-blower will have highly developed personal ethics and be tenacious. Perhaps these two qualities are not dispositional variables, but they are likely needed to survive a whistle-blower's position.

\section{Doing the right thing}

Whether anyone is a potential fraudster or whistle-blower is not clear at first, to no one. The potential whistle-blower has to make a choice, at an early stage, to discuss the situation or not, and with whom. Making suspected healthcare fraud open to discussion, for the first time, does not necessarily have to escalate the situation, but ultimately it can have major consequences. It is an extremely complex issue where the impact and size are hardly known at the outset. What is the right thing to do at what point? On the one hand, Ogunbanjo \& van Bogaert state, "Healthcare fraud is also not a victimless crime. Therefore, healthcare professionals must inform on colleagues who practice it" (Ogunbanjo \& van Bogaert 2014:13). But on the other hand, Mannion states that whistleblowing has "many complex and ambiguous aspects that need to be considered as part of the broader (organisational) cultural dynamics of healthcare institutions" (Mannion 2015:503). Blowing the whistle can have a butterfly effect; a small action can cause major change (Gleick 2011, Dooley 2009). What happens when the suspected fraudster is asked about the alleged fraud is a sensitive matter. The response depends on the initial conditions, which include the relationship between the suspected fraudster and potential whistle-blower: stable/unstable, full of/lacking in confidence and equal/unequal. A small change initiated by a whistle-blower carefully bringing up suspected fraud can result in significant differences later on, as happened in the Gotlieb case. One can think of dismissal, damaged mutual trust or a lawsuit against the whistle-blower. It is therefore quite conceivable that the potential whistle-blower would feel unsure about what is the right thing to do. At the time of the first confrontation with possible fraud, there are no clues as to the scale or impact of this confrontation. In this case, one can fall back on the professional code of ethics, which can be traced back to the Geneva Declaration (based on the Hippocratic oath) and the Code of Medical Ethics. The World Health Organization advises following ethical principles: 
Table 1: Ethical principles pertaining to the World Health Organization

\begin{tabular}{|l|l|}
\hline Integrity & $\begin{array}{l}\text { To behave in accordance with ethical principles, and act } \\
\text { in good faith, intellectual honesty and fairness. }\end{array}$ \\
\hline Accountability & $\begin{array}{l}\text { To take responsibility for one's actions, decisions and } \\
\text { their consequences. }\end{array}$ \\
\hline $\begin{array}{l}\text { Independence } \\
\text { and }\end{array}$ & $\begin{array}{l}\text { To conduct oneself with the interests of WHO only in } \\
\text { view and under the sole authority of the Director- } \\
\text { General, and to ensure that personal views and } \\
\text { convictions do not compromise ethical principles, official } \\
\text { duties or the interests of WHO. }\end{array}$ \\
\hline Respect & $\begin{array}{l}\text { To respect the dignity, worth, equality, diversity and } \\
\text { privacy of all persons. }\end{array}$ \\
\hline $\begin{array}{l}\text { Professional } \\
\text { commitment }\end{array}$ & $\begin{array}{l}\text { To demonstrate a high level of professionalism and } \\
\text { loyalty to the Organization, its mandate and objectives. }\end{array}$ \\
\hline
\end{tabular}

However, in the case of presumed healthcare fraud, the virtues or principles of 'integrity' and 'professional commitment' can create a field of tension for a potential whistle-blower. In the eyes of the fraudster, acting in accordance to ethical principles (being honest and acting in good faith) may conflict with the interests of the healthcare organization. Uys \& Senekal say that whistle-blowers are confronted by a severe dilemma, having to choose between the morality of principle and the morality of loyalty. But, they also claim, "If any of the options were believed to be of higher moral value than the other, then the dilemma would theoretically disappear" (Uys \& Senekal 2008:39). In Morality of principle versus morality of loyalty: The case of whistleblowing the authors take a closer look at the distinction between the two moralities developed by Bredemeier \& Stephenson (1967).

The morality of loyalty within the organisational context states that it is right or proper for employees to be loyal to their organisations. The morality of principle, on the other hand, defines it as 'morally good' to act in accordance with certain abstract principles (in this context typically the legal or ethical requirements applicable to the organisational context) irrespective of the people involved (Uys \& Senekal 2008:39).

In the ideal situation, Uys \& Senekal state, congruent morality is the case, and the moralities of principle and loyalty are equal. In the case of healthcare fraud, where there is a fraudster and a whistle-blower, the fraudster deviates from both moralities while the whistle-blower deviates from the morality of loyalty but conforms with the morality of principle. In other words, the whistle-blower puts the morality of principle above the 
morality of loyalty. Theoretically, as stated above, the whistle-blower no longer has a dilemma. But in most cases, when colleagues still assume that both moralities are equal, deviating from the morality of loyalty does indeed evoke a considerable emotional dilemma. Even if the whistle-blower takes great care in revealing the alleged fraud, colleagues can experience this deviation as disloyalty and distance themselves from the person concerned. The whistle-blower in turn could risk their job and social connection with colleagues. However, doing nothing can result in more healthcare fraud, which can have consequences for the amount of money available for spending on needed care.

To deepen the investigation into this dilemma, it can be useful to refer to the 'vita activa', the distinction Hannah Arendt draws between labor, work and action in her book The Human Condition (Arendt 1958):

With the term vita activa, I propose to designate three fundamental human activities: labor, work, and action. They are fundamental because each corresponds to one of the basic conditions under which life on earth has been given to man (Arendt 1958:7).

For Arendt, labor is a cyclical process that is necessary for selfpreservation and the reproduction of the human species. Work, however, is a linear process with a clear beginning and end. It is what we produce, for instance healthcare, therapy, healthcare management or healthcare administration. Action is the means by which humans disclose themselves and humans can distinguish themselves from others. It includes speech and act; it reveals who you are as a human being. Through action and speech, the unique character traits of a person become apparent. Where labor is cyclic and work is linear, action has no clear boundaries and can have consequences that cannot be foreseen or can be overlooked. Action has no beginning or end and its consequences can change over time.

To translate this into the case of healthcare fraud and specifically to the question of what is the right thing to do, Arendt's distinction between work and action is relevant. Work is the world of homo faber "where everything must be of some use" (Arendt 1958:154). It is about production, in this case producing healthcare within a healthcare organization. Work is about the ability to maintain an environment fit for human use. It is about doing things according to established procedures and customs. The right procedures are taught during vocational training and repeated over time. Matching procedures is the Code of Medical Ethics. In the linear environment of work, you have to follow procedures. They can be internal procedures, 
such as fraud prevention or fraud control procedures or following the Code of Medical Ethics. If a whistle-blower wants to discover what the right thing to do is, they have to follow these procedures, these ethical principles. But in complex cases where much is at stake, simply following procedure is rarely enough. It is not incomprehensible that in unique, complex situations standard procedures and ethical principles will not provide sufficient guidance for the whistle-blower to know what the right thing is to do. What if the internal supervisory board only refers to internal procedures, the fraudster threatens to fire the whistle-blower, or the external state supervisors want to see hard evidence before accepting the case? The potential whistle-blower still does not know what the right thing is to do...

Then action comes in. Action is accompanied by uncertainty, unpredictability and irreversibility. If someone blows the whistle by speaking out, they take action. In contrast to the linearity of work, action is the first step of an uncontrollable chain reaction. As Morin says, "The domain of action is very risky, very uncertain. It imposes on us a very keen awareness of risks, derailments, bifurcations, and imposes a reflection on complexity itself" (Morin 2008:55). Action is irreversible. Telling the fraudster that (presumed) fraud has been noticed cannot be undone. The relationship between fraudster and whistle-blower is changed, for better or worse. After action, the reaction - and the chain of following reactions - is unpredictable. Is action something to hold back on because of its unpredictability and irreversibility? According to Arendt, the answer is no. "The fact that man is capable of action means that the unexpected can be expected from him, that he is able to perform what is infinitely improbable" (Arendt 1958:178). This is what makes us rise above the standards of work, with all its guidelines and procedures. From this line of thinking, an action like blowing the whistle is, on the one hand, scary because of its unpredictability and irreversibility. But on the other hand, it is what makes us human. It encourages us to be more than a 'puppet on a string.' In other words, Arendt encourages us to speak out and take action. If we do not want to live only by procedures we have to speak out, we have to take action. Knowing - about fraud - and wanting to be a human means taking action. Doing the right thing is therefore strongly related to our position in society. This not only applies to whistle-blowers, but to anyone else involved, such as the internal supervisory board, the external state supervisors as well as government and of course the fraudster. At worst, the whistle-blower is the only one who speaks out and acts. But in the best case many more who are involved take action and a dialog is started. The situation can be discussed from different angles and led to a new beginning. The plurality of actors and opinions is needed to understand what is 
revealed and what it can mean. By sharing different perspectives, we are able to "see reality in the round and develop a shared common sense" (Canovan introducing Arendt 1958:xni).

Whistle-blowers do not own the truth, nor are they just liars. Blowing the whistle is not about revealing fraud or being a hero by definition. Blowing the whistle in suspected healthcare fraud is acting like a socially and politically engaged human being. By taking action, you open up the space for other perspectives and discussion.

This raises a question concerning 'doing the right thing'. Is there a logical or even necessary sequence in what to do first? Should the healthcare professional who suspects healthcare fraud start by following standard internal procedures within the framework of what Arendt calls work? Then, only if this first step proves insufficient, should the next step can be taken, namely, to switch to external procedures. And if that has insufficient effect should the whistle-blower make the information public? This may suggest that if the whistle-blower does not get their way with the internal procedures, they would seek further. Ultimately, this person risks identifying themselves with the classic image of a whistle-blower: as a victim of those in power. This trajectory starts looking as if it more about being heard or even recognized as a whistle-blower, instead of the disclosure of information to gain more perspectives on this information. When someone speaks out in the public realm, providing information about suspicions of healthcare fraud, and is not open to other perspectives... this person is actually lingering in the social domain of procedures and will feel frustration that things are not going the way they want. This is not what Arendt means by action and becoming "who you are". Who you are, is formed by the exchange of information in contact with others in the public realm (Arendt 1958). For reality is constituted in the public realm, where there is freedom of action and speech and there is uncertainty as to what others will do with this disclosure of information. Action has to take place in interaction with others. If a whistle-blower does not open up to other perspectives, they do not take action in the sense of what Arendt means by action.

Whistleblowing is emphatically not about making judgments. Although it is tempting to link to whistleblowing in line with Arendt's ideas about judgment, whistleblowing is about acting and not about judging. If someone who suspects healthcare fraud keeps quiet, the suspicion lingers proverbially. The suspicion persists, it is not refuted or confirmed. Whistleblowing can start a new discussion and is (just) one of the many perspectives necessary to make a sound judgment. 
In summary, a healthcare professional and potential whistle-blower can stay within the lines of work and 'just follow procedure'. If nothing changes or the whistle-blower is fired, so be it. But if the healthcare professional wants to be a human being, not just an employee, they should take action. This action entails uncertainty and unpredictability, which can make a whistle-blower feel anxious and vulnerable. It is therefore necessary that the whistle-blower is not the only one who acts and speaks out. All involved should take action and speak out. The plurality of opinions and perspectives helps to develop a common sense. In the framework of being human, being socially and politically engaged, action is the right thing to do, and while doing it, one hopes all relevant stakeholders will do it too...

\section{Doing things right}

If one blows the whistle, takes action, how should one operate? Where to start and what to do next? In the event of blowing the whistle on suspected healthcare fraud, the situation is complex and dynamic, almost exclusively in every case. A healthcare facility or organization has the key features of a complex adaptive system, meaning that the interactions of all its actors are unpredictable and often unique (Sturmberg \& Martin 2010). Different shared values (attractors) are involved (Sturmberg, O'Halloran, \& Martin 2012). There are economic interests, scientific guidelines, humanitarian and emotional interests, declaration rules from the health insurer and national statutory rules, each interacting in an unpredictable way. A whistleblowing case is also attached to individuals, with their own professional and personal history, idiosyncrasies and mutual relationships (Mannion \& Davies 2015). Each situation is unique, so it is hard to develop a one-size-fits-all plan for blowing the whistle.

Brian Martin (2013) managed to write a practical guide for whistleblowers, based on what almost all whistleblowing cases have in common. He begins with a warning of pitfalls such as trusting too much, having not enough evidence and not building support. He emphasizes that a whistleblower must be well prepared. Martin lays stress on what a whistle-blower should expect in consequence. "Whistleblowing can have devastating consequences for health, finances and relationships" (Martin 2013:229). But still, the question remains: where to start and what to do next? Where Martin focuses on pitfalls and learning from previous experiences of fellow sufferers, the Cynefin Framework can be of help in analyzing the complexity of the situation (Kurtz \& Snowden 2003, Snowden \& Boone 2007). The decision model of the Cynefin Framework gives advice on how to respond. It can help by categorizing the situation in five domains: 'simple or obvious', 'complicated', 'complex', 'chaotic' and 'disorder/confused'. Every domain 
has its own cause-effect relationship and needs a different response. This framework will not solve problems but it can guide the whistle-blower while taking action. To be clear, the Cynefin Framework does not start from the feelings and thoughts of the whistle-blower; the situation is the starting point. This is an important distinction because a situation can be simple yet still evoke complex feelings. A situation, in this case a suspected healthcare fraud, consists of many actors who jointly provide a certain dynamic. In this situation, the whistle-blower is just one of the actors.

An essential part of using the Cynefin Framework is to develop a support group, as it is needed to organize the "plurality of actors and opinions to understand what is revealed and what it can mean", in line with Arendt (Canovan introducing Arendt, 1958:xni). Also, in line with Martin, a support group is needed to keep the whistle-blower out of the pitfall of not building support. The support group discusses all the factors that influence the situation and its dynamic. The support group judges which part of the situation fits which domain. In the end, the domain gives the whistle-blower advice on how to respond.

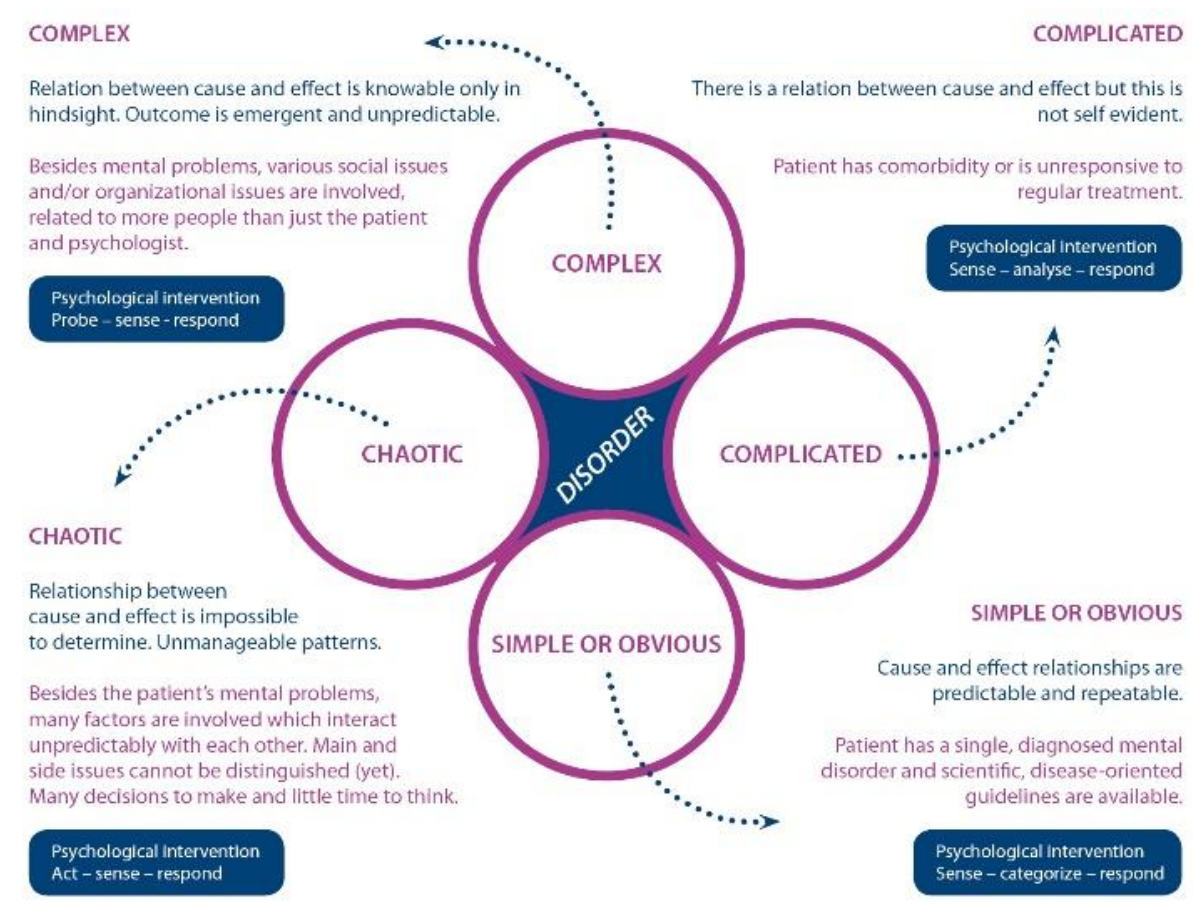

Figure 1. Cynefin Framework

To explain the five domains of the Cynefin Framework and its decision model related to disclosure of healthcare fraud, some practical examples follow. The first domain is disorder, when the situation is confusing. Example: in the beginning, when healthcare fraud is suspected, not all information is clear, perspectives switch frequently, and laws and 
regulations are mostly unfamiliar. The support group disagrees strongly about where the situation fits in the framework. Individuals in the support group may be inclined to place the situation in their favorite domain. But 'disorder' is also where a good discussion gets started. The decision model advises acknowledging that it is not (yet) clear which part of the situation fits in which domain. After this acknowledgment, it is time to break the situation into smaller parts, make sense of its parts and agree on where each part fits in the framework. Possibly some parts are simple and other parts are complicated, complex or even chaotic.

The second domain is simple. Example: charging for services not provided or claiming phantom bills. In this domain the relationship between cause and effect is clear and not open to dispute. There is enough knowledge about the subject. The decision model advises making sense of the given information (e.g. the phantom bill), categorizing that data and responding to existing knowledge. Discuss the facts, for example the phantom bill, with those who are responsible for declarations to the health insurer.

The third domain is complicated. Here there is a relationship between cause and effect but on first sight it is not yet fully known or known only by a few. Example: providing unnecessary services or claiming more refunds than appropriate for the care that is given. What is necessary or appropriate and what not is debatable and open to multiple interpretations. In a complicated situation the whistle-blower is dependent on experts. These experts can support the fact-finding and experiments can make cause-effect relationship more apparent. To do the right thing, the decision model advises making sense of all information, analyzing it and responding in accordance with expert advice.

The fourth domain is complex. Here too there is a cause-effect relationship, but because of the high number of agents and their underlying interactions the pattern can change over time. This means the pattern is unpredictable and can only be knowable on hindsight. Example: when employees widely support a healthcare vision that is actually a cover for healthcare fraud. Healthcare professionals can be unaware of healthcare fraud because their focus is on the widely supported healthcare vision. Propagating a humane healthcare vision, on the one hand, and healthcare fraud on the other - performed by one's manager - is not what employees expect. The decision model here is to create probes before taking action, in a process of trial and error. To take some small action and see what happens until a pattern becomes clearer. It is necessary to do this from several perspectives, so not only from the perspective of 'he is a fraud' but also from 'he is acting in good faith' or 'he does not know what his acts mean or 
what the consequences are'. After a while the pattern will become apparent. Does the fraudster often lie or does he act without knowing the rules?

The last domain is chaos, where there is no relationship between cause and effect to discover. For the whistle-blower this can arise in an unclear and elusive situation. Example: when the fraudster accuses the whistle-blower of disloyalty and defamation and a lot of uncertainty arises within the team on whom to believe. When a situation is chaotic, one must act 'quickly and decisively'. The whistle-blower can try to gain control over the situation (authoritarian actions) or create their own pattern, for example based on their moral principles.

By using the Cynefin Framework, the whistle-blower tries to unfold the intertwined situation based on the information there is or can be obtained. The puts the situation in focus and the goals are collecting information and different perspectives. The support group organizes the importance of collecting many different perspectives. 'Doing things right' is motivated by the decision model associated with the several domains and based on many different perspectives.

\section{Conclusions and discussion}

When a healthcare professional is confronted by possible healthcare fraud, in most cases they will be overwhelmed by opinions, questions and emotions. Whether an act really is fraud depends on many factors and most times is a gray area. Healthcare fraud ranges from unintentionally charging too much for service given to kickback schemes and intentionally upcoding declarations for healthcare providers. Who becomes a whistle-blower is determined by situational variables and not the specific characteristics of a person. However, more than likely a fraudster has several recognizable features, such as low personal ethics and the ability to rationalize their [fraudulent] acts.

Not many stories about whistle-blowers have a happy ending. That is why it is important to reflect on the questions of 'doing the right thing' and 'doing things right'. Someone could limit themselves to what Hannah Arendt calls work and only follow procedures. The right thing to do, Arendt promotes, is to act: to speak out and start a discussion on the subject. Blowing the whistle in the case of suspected healthcare fraud is acting like a socially and politically engaged human being. By acting, the whistleblower opens up space for other perspectives and discussion. To do this acting - in the right way means that the whistle-blower should organize a support group right from the start. This support group facilitates the collection of different perspectives and keeps the focus on the situation; not 
just on the feelings and opinions of the fraudster, whistle-blower and friends. Using the Cynefin Framework supports the trajectory from 'not knowing where to begin' (disorder) to analyze the situation and respond accordingly to the complexity of the issue. Just like any other model or framework the Cynefin Framework offers only basic handles. When confronted with suspected healthcare fraud, the main lessons are: create a support group; collect different perspectives; realize that the views of the whistle-blower are just one perspective; focus on the given situation rather than the emotions of the persons in question; divide the situation into its component parts and place them in one or other of the domains; then respond according to the decision model belonging to this domain.

Doing the right thing (acting) and doing things right (avoiding pitfalls/using the Cynefin Framework) still do not guarantee a happy ending. Doing the right thing in the case of revealing healthcare fraud and doing things right will always be a path of painful uncertainty. The whistle-blower will always stay dependent on others. Is every relevant and involved person or institution willing to take action? 


\section{Notes}

1 PhD candidate Radboud University Nijmegen, Netherlands European Forum for Primary Care, working group Mental Health Director Steunpunt GGZ (Fulcrum Mental Health), Utrecht, Netherlands. E-mail: e.h.smit@4sophia.nl; Orcid-iD: https://orcid.org/0000-0002-8322-8793

2 Emeritus Professor Clinical Psychology and Pschotherapy - Radboud University Nijmegen, Department Social Sciences, Netherlands. E-mail: jjlderksen@planet.nl; Orcid-iD: https://orcid.org/0000-0002-1766-7640 


\section{References}

Ainsworth, P.B. (2001). Offender profiling and crime analysis. Portland, Oregon: Willan Publishing.

Arendt, H. (1958). The human condition. New York.

Bredemeier, H. C. \& Stephenson, R.M. (1967). The analysis of social systems. New York: Holt, Rinehart and Winston.

Brooks, G., Tunley, M., Button, M., \& Gee, J. (2017). Fraud, error and corruption in healthcare: a contribution from criminology.

Byrd, J., Powell, P., \& Smith, D. (2013). Health care fraud: An introduction to a major cost issue. Journal of Accounting, Ethics and Public Policy, 14(3). Page 524.

Coleman, J. W. (1987). Toward an integrated theory of white-collar crime. American Journal of Sociology, 93(2), 406-439.

Cressey. D.R (1950): The Criminal Violation of Financial Trust. American sociological review 15 (6) pp 738-743, December. Pp 1-15 retrieved from www.jstor.org.

Dooley, K. J. (2009). The Butterfly Effect of the" Butterfly Effect". Nonlinear dynamics, psychology, and life sciences, 13(3), 279.

EHFCN. Waste typology matrix: European Healthcare Fraud and Corruption Network. 2016. https://ehfen-powerhouse.org/groups/ 4-ehfen-wastetypology-matrix/welcome.

European Commission (2013). Study on Corruption in the Health Sector. HOME/2011/ISEC/PR/047-A2, October 2013. Retrieved on 30th March 2020 from https://ec.europa.eu/home-affairs/sites/homeaffairs/files/what-isnew/news/news/docs/20131219 study on corruption in the healthcare sector en.pdf

Gleick, J. (2011). Chaos: Making a new science. Open Road Media.

Kalcheva, K. (2015). Whistleblowing and the NZA case: Managing change and Human Resources. Anchor Academic Publishing.

Kurtz, C. F., \& Snowden, D. J. (2003). The new dynamics of strategy: Sense-making in a complex and complicated world. IBM systems journal, 42(3), 462-483. 
Mannion, R., \& Davies, H. T. (2015). Cultures of silence and cultures of voice: the role of whistleblowing in healthcare organisations. International journal of health policy and management, 4(8), 503.

Martin, G. (n.d.). "Whistle-blower" - the meaning and origin of this phrase. Retrieved on 23 March 2020, on https://www.phrases.org.uk/meanings/whistle-blower.html.

Nader, R., Petkas, P., \& Blackwell, K. (1972). Whistleblowing. NY.

Ogunbanjo, G. A., \& van Bogaert, D. K. (2014). Ethics in health care: healthcare fraud. South African Family Practice, 56(1), S10-S13.

Sauter, W., Mikkers, M., Vincke, P., \& Boertjens, J. (2017). Healthcare fraud, corruption and waste in Europe: National and academic perspectives.

Sehgal, P. (2017) Can Whistleblowers live 'Happily Ever After?' A Review of Literature on Whistleblowing and its Implications. 1,s.I.: IRJMST,2017, International Research Journal of Management Sciences \& Technology, Vol.8.

Smit, E. (2017). De klok luiden doe je niet in een ongeloofwaardig overheidshuis. Follow the Money. Retrieved on 23 March 2017, from https://www.ftm.nl/artikelen/klok-luiden-niet-inoverheidshuis?share $=$ XK7DSDkVOqhFhJovFa\%2FM9F3AEgIMVIbn5h\%2B \%2FXOcfbuqKjYKofYdHsdYj\%2Fh8\%3D.

Snowden, D. J., \& Boone, M. E. (2007). A leader's framework for decision making. Harvard business review, 85(11), 68.

Sorunke, O. A. (2016). Personal ethics and fraudster motivation: The missing link in fraud triangle and fraud diamond theories. International Journal of Academic Research in Business and Social Sciences, 6(2), 159165.

Starkey, P. L. (2000). Whistleblowing behavior: The impact of situational and personality variables.

Sturmberg, J. P., \& Martin, C. M. (2010). The dynamics of health care reform--learning from a complex adaptive systems theoretical perspective. Nonlinear dynamics, psychology, and life sciences, 14(4), 525540.

Sturmberg, J. P., O'Halloran, D. M., \& Martin, C. M. (2012). Understanding health system reform - a complex adaptive systems perspective. Journal of evaluation in clinical practice, 18(1), 202-208. 
Thompson D. (2013). Two concepts of corruption: Edmond J Safra Center for Ethics.

http://ethics.harvard.edu/working- papers-series.

Thornton, D., Brinkhuis, M., Amrit, C., \& Aly, R. (2015). Categorizing and describing the types of fraud in healthcare. Procedia Computer Science, 64, 713-720.

Uys, T., \& Senekal, A. (2008). Morality of principle versus morality of loyalty: The case of whistleblowing. African Journal of Business Ethics, 3(1).

World Health Organization. (n.d.). Ethical principles. Retrieved on 30th March 2020, fromhttps://www.who.int/about/ethics/ethical-principles. 